\title{
The effect of bee prepolis on primary dysmenorrhea: a randomized clinical trial
}

\author{
Ensiyeh Jenabi ${ }^{1}$, Bita Fereidooni ${ }^{2}$, Manoochehr Karami ${ }^{3}$, Seyedeh Zahra Masoumi ${ }^{4}$, Mahdi Safari ${ }^{5}$, \\ Salman Khazaei ${ }^{6}$
}

\begin{abstract}
${ }^{1}$ Autism Spectrum Disorders Research Center, Hamadan University of Medical Sciences, ${ }^{2}$ Midwife in Social Security Organization, ${ }^{3}$ Research Center for Health Sciences, Hamadan University of Medical Sciences, ${ }^{4}$ Mother and Child Care Research Center, School of Nursing and Midwifery, Hamadan University of Medical Sciences, ${ }^{5}$ Medical Degree in Social Security Organization, ${ }^{6}$ Research Center for Health Sciences, Hamadan University of Medical Sciences, Hamadan, Iran
\end{abstract}

\section{Objective}

Primary dysmenorrhea typically occurs with no associated pelvic pathology and is common in adolescents and young women. This study evaluated the effect of bee propolis on relief of primary dysmenorrhea.

\section{Methods}

The study was performed in 2018 in Hamadan, in western Iran, among female students with primary dysmenorrhea. Participants were randomly divided into two groups, using balanced block randomization, and were administered a placebo or bee propolis capsules for 5 days during two menstruation cycles. The number of participants required was estimated to be 86 in total, with 43 students in each group according to the inclusion criteria. We used the visual analog scale to assess pain severity. The independent $t$-test was conducted for comparing between two groups, using SPSS 16.0.

Results

A significant change was found in the mean pain scores during the first $(P<0.001)$ and second $(P<0.001)$ months after using bee propolis in comparison with placebo. The means of the pain scores in the bee propolis group were $5.32 \pm 2.28$ and $4.74 \pm 2.40$ in first and second months after the intervention, respectively, whereas the means of the pain scores in the placebo group were $7.40 \pm 1.21$ and $7.17 \pm 1.24$ in first and second months after the intervention, respectively.

\section{Conclusion}

Our study showed that the use of bee propolis for two months compared with placebo reduced primary dysmenorrhea during the first and second months after use, with no adverse effects. Therefore, it could be used as an alternative to nonsteroidal anti-inflammatory drugs for relief of primary dysmenorrhea.

Keywords: Bee propolis; Primary dysmenorrhea; Adolescent

\section{Introduction}

There are 2 types of dysmenorrhea: primary and secondary. Primary dysmenorrhea typically occurs with no associated pelvic pathology, and is common in adolescents and young women [1]. The prevalence of primary dysmenorrhea ranges from $60-93 \%$ [2]. Secondary dysmenorrhea is due to an organic pathology in the uterus, such as endometriosis. The risk factors for primary dysmenorrhea are an age younger than 20 years, a family history of dysmenorrhea, smoking, heavy bleeding, irregular bleeding, menarche age younger than 12 years, low body weight, and nulliparity [2-4]. The
Received: 2018.12.01. Revised: 2019.02.02. Accepted: 2019.05.02. Corresponding author: Bita Fereidooni

Midwife in Social Security Organization, Jahannama street, Shahbazi policlinic, Hamadan, Iran

E-mail: barshimah@yahoo.com

https://orcid.org/0000-0002-8436-4076

Articles published in Obstet Gynecol Sci are open-access, distributed under the terms of the Creative Commons Attribution Non-Commercial License (http://creativecommons. org/licenses/by-nc/3.0/) which permits unrestricted non-commercial use, distribution, and reproduction in any medium, provided the original work is properly cited.

Copyright $\odot 2019$ Korean Society of Obstetrics and Gynecology 


\section{Obstetrics \& Gynecology Science}

Ensiyeh Jenabi, et al. The effect of bee prepolis on primary dysmenorrhea

cause of pain in primary dysmenorrhea is excess production of prostaglandins in the uterus during the ovulatory cycle, which leads to uterine contraction and ischemia [5]. Nonsteroidal anti-inflammatory drugs (NSAIDs) and oral hormonal contraceptives are suggested for reducing the symptoms of dysmenorrhea; however, these drugs can have serious adverse effects in some women [6]. NSAID therapy can increase renal, cardiovascular, and gastrointestinal complications. The most common gastrointestinal complications include heartburn, stomach pain, nausea, vomiting, diarrhea, and constipation [7]. Various studies have reported on alternative and complementary medicine methods for relief of primary dysmenorrhea, including herbal and dietary therapies, behavioral interventions, acupressure, spinal manipulation, transcutaneous electrical nerve stimulation, and acupuncture $[5,8,9]$.

Amiri Farahani et al. [10] have shown that honey and mefenamic acid capsules had a similar pain relief effect among women with primary dysmenorrhea; a study by Golder [11] found that bee propolis improved chronic backache and hip pain as well as fresh injuries to muscles and tendons.

Bee propolis has been used in traditional Iranian medicine for relieving menstrual pain [12]. Recent studies have reported that propolis contains elevated amounts of a certain type of isoflavonoid, i.e., isoflavones. This particular group of polyphenols exhibits a wide range of biological properties, including antiviral, antimicrobial, anti-inflammatory, and even anticancer activities $[13,14]$. Three derivatives of $p$-coumaric acid isolated from a Brazilian sample have shown a relaxant effect on smooth muscle by propolis [15]. Therefore, propolis can be effective in reducing uterine pain through its antiinflammatory and antispasmodic effects $[16,17]$.

As for the trend of women to use herbal drugs and not preform of similar study in the Iran, therefore, the present study was conducted to evaluate the effect of bee propolis compared with placebo on primary dysmenorrhea in students from Hamadan University of Medical Sciences.

\section{Materials and methods}

\section{Study design}

The present study was a double-blind randomized controlled trial conducted on 86 students from the Hamadan University of Medical Sciences (Hamadan, Iran) in 2018.

The students were randomized to 2 treatment groups by a computer program using the rand command. The placebo group received a 500-mg starch capsule taken daily from 2 days before menstruation until the third day of menstruation, for 2 cycles. The bee propolis group received a 500-mg bee propolis capsule (Shahd Golha Honey Company, Isfahan, Iran) taken daily from 2 days before menstruation until the third day of menstruation, for 2 cycles.

\section{Eligibility criteria}

We included students with the following criteria: 1) single; 2) 19-23 years of age; 3 ) a history of regular menstruation; 4) use of no other medication for alleviation of dysmenorrhea; 5) no use of hormonal drugs; 6) no clinical history of major psychological disorders; 7) consecutive menstrual cycles; and 8) pain score 3 and higher based on visual analog scale (VAS). Exclusion criteria were intolerance to drug use and improper use of drugs or use discontinuation. Ultrasound was used to rule out secondary dysmenorrhea. All students provided written consent.

\section{Participant characteristics}

We used a researcher-designed questionnaire including age, menarche age, and body mass index (BMI). The students completed a baseline assessment using a 10-mm VAS for evaluating pain, with 0 representing no pain and 10 representing the worst possible pain.

\section{Sample size}

According to the sample size in similar interventional studies on primary dysmenorrhea [18] and with the probability of anticipating a $10 \%$ loss to follow-up, $b=0.2$ and $a=0.05$, the number of participants required was estimated to be 86 in total, with 43 students in each group according to the inclusion criteria.

\section{Data analysis}

The quantitative variables are presented as mean \pm standard deviation. Normality of data was assessed using the Kolmogorov-Smirnov test. Continuous variables between the two groups were compared using Student's t-test. All the analyses were conducted using SPSS (version 23) (IBM Corp., Armonk, NY, USA). We considered a $P$-value of less than 0.05 as significant. 


\title{
Obstetrics \& Gynecology Science
}

\author{
Vol. 62, No. 5, 2019
}

\section{Results}

In this study, of 126 students evaluated for eligibility, 40 did not meet the inclusion criteria, and thus were excluded. Therefore, a total of 86 students (43 per group) were included, of which 3 in the placebo group did not return for follow-up. Thus, 43 students in the bee propolis group and 40 students in the placebo group were evaluated (Fig. 1). The mean ages of the students in the placebo and bee propolis groups were $21.32 \pm 1.30$ and $21.07 \pm 1.58$ years, respectively; the mean menarche ages in the placebo and bee propolis groups were $12.15 \pm 1.23$ and $12.48 \pm 1.30$ years, respectively; and the mean BMls in the placebo and bee propolis groups were $24.27 \pm 2.40$ and $23.51 \pm 3.03 \mathrm{~kg} / \mathrm{m}^{2}$, respectively. There was no significant difference between the 2 groups in base-

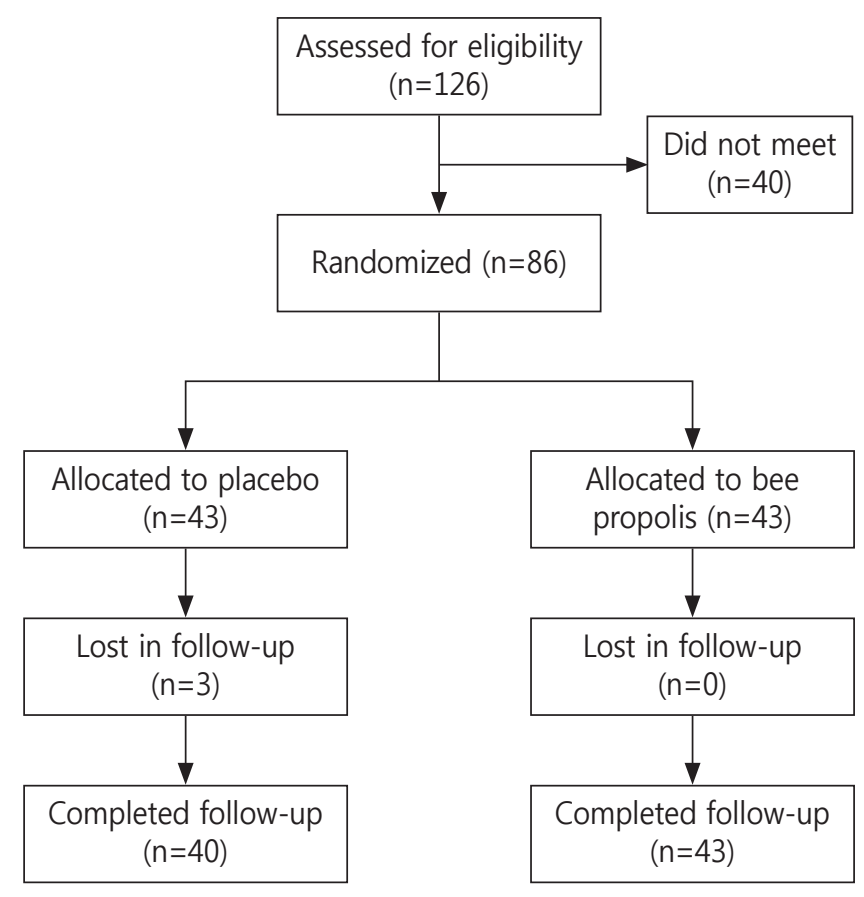

Fig. 1. Flowchart of the trial.

Table 1. Characteristics of students in both groups

\begin{tabular}{|c|c|c|c|}
\hline Characteristics & $\begin{array}{c}\text { Placebo } \\
\text { group }(n=40)\end{array}$ & $\begin{array}{l}\text { Bee propolis } \\
\text { group }(n=43)\end{array}$ & $P$-value \\
\hline Age (yr) & $21.32 \pm 1.30$ & $21.07 \pm 1.58$ & 0.410 \\
\hline Menarche age (yr) & $12.15 \pm 1.23$ & $12.48 \pm 1.30$ & 0.421 \\
\hline $\mathrm{BMI}\left(\mathrm{kg} / \mathrm{m}^{2}\right)$ & $24.27 \pm 2.40$ & $23.51 \pm 3.03$ & 0.241 \\
\hline
\end{tabular}

Data are shown as mean \pm standard deviation.

$\mathrm{BMI}$, body mass index. line characteristics (Table 1).

Table 2 presents pain scores before and at the first and second months after the intervention in the placebo and bee propolis groups. The means of the pain scores in the bee propolis group were $5.32 \pm 2.28$ and $4.74 \pm 2.40$ in first and second months after the intervention, respectively, whereas the means of the pain scores in the placebo group were $7.40 \pm 1.21$ and $7.17 \pm 1.24$ in first and second months after the intervention, respectively. A significant change was found in the mean pain scores during the first $(P<0.001)$ and second $(P<0.001)$ months after using bee propolis compared with placebo. Table 3 shows the comparison of changes in dysmenorrhea scores between the first (cycle 0-cycle 1) and the second (cycle 0-cycle 2) cycles, which were significant $(P<0.001)$. In present study, no adverse effects were reported after bee propolis use.

\section{Discussion}

Our study showed that the daily use of a 500-mg capsule of bee propolis compared with placebo decreased primary

Table 2. Comparison of changes in mean dysmenorrhea scores in both groups

\begin{tabular}{lccc}
\hline Characteristics & $\begin{array}{c}\text { Baseline } \\
\text { (cycle 0) }\end{array}$ & $\begin{array}{c}\text { 1 month later } \\
\text { (cycle 1) }\end{array}$ & $\begin{array}{c}\text { 2 months } \\
\text { later (cycle 2) }\end{array}$ \\
\hline $\begin{array}{l}\text { Treatment } \\
\begin{array}{l}\text { Bee propolis } \\
(\mathrm{n}=43)\end{array}\end{array}$ & $6.86 \pm 1.79$ & $5.32 \pm 2.28$ & $4.74 \pm 2.40$ \\
$\begin{array}{l}\text { Placebo }(\mathrm{n}=40) \\
\text {-value }^{\text {a) }}\end{array}$ & $7.45 \pm 1.33$ & $7.40 \pm 1.21$ & $7.17 \pm 1.24$ \\
\hline
\end{tabular}

Data are shown as mean \pm standard deviation.

${ }^{a}$ Comparison between experimental and placebo groups (independent $t$-test).

Table 3. Comparison of changes of dysmenorrhea scores between the first and second cycles

\begin{tabular}{lcc}
\hline Characteristics & Cycle 0-cycle 1 & Cycle 0-cycle 2 \\
\hline Treatment & & \\
Bee propolis $(n=43)$ & $1.53 \pm 1.58$ & $2.11 \pm 1.66$ \\
Placebo $(n=40)$ & $0.05 \pm 1.08$ & $0.27 \pm 1.26$ \\
P-value $^{\text {a) }}$ & $<0.001$ & $<0.001$
\end{tabular}

Data are shown as mean \pm standard deviation.

${ }^{\text {a) }} P$-value was calculated based $t$-test independent. 


\section{Obstetrics \& Gynecology Science}

Ensiyeh Jenabi, et al. The effect of bee prepolis on primary dysmenorrhea

dysmenorrhea during the first and second months after use. Therefore, it can be an alternative to NSAIDs for relief of primary dysmenorrhea; no adverse effects were observed during its use.

Until now, no studies about the effect of bee propolis on dysmenorrhea had been conducted; however, some studies had shown the effect of honey on relief of primary dysmenorrhea. A study by Amiri Farahani et al. [10] in Iran was conducted for comparison of honey with mefenamic acid for pain relief among women with primary dysmenorrhea. They reported that honey and mefenamic acid capsules had a similar effect for pain relief [10]. In 2004, Meda et al. [3] reported that honey and honeybee larvae were used for treating period pains and postnatal disorders among women; Golder [11], also in 2004, reported that bee propolis treated chronic backache, hip pain, and fresh injuries of muscles and tendons.

Another study reported on traditional methods for relief of dysmenorrhea. This study evaluated the effect of Menstrugole on primary dysmenorrhea. They reported a significant change in the mean pain score during the first and second cycles after the use of Menstrugole compared with the placebo. Therefore, Menstrugole decreased pain severity in female students [8].

This study had some limitations. For example, the small sample size; the difference between the trial groups with less possibility of random error was observed by the sample size of large. Another limitation was the short study period. We evaluated adverse effects of bee propolis use for only 2 months. Therefore, there could be a possibility of bias. Also, this study was performed on single adolescents and cannot be generalized to other age groups. Therefore, we suggest that further studies be conducted in other countries and in different age groups.

Traditional methods have been preferred by Iranian women to modern methods for relieving primary dysmenorrhea, and the present study showed that bee propolis is effective for relief of this pain. Most NSAIDs used in long-term therapy have exerted severe adverse effects [19]; however, bee propolis showed no adverse effects. Therefore, bee propolis can be used as an alternative to NSAIDs for relief of primary dysmenorrhea.

In conclusion, our study showed that the use of bee propolis for 2 months compared with placebo reduced primary dysmenorrhea during the first and second months after use, with no adverse effects. Therefore, it can be used as an alternative to NSAIDs for relief of primary dysmenorrhea.

\section{Acknowledgments}

We would like to thank the Vice-chancellor of Research and Technology, Hamadan University of Medical Sciences, for financial support.

\section{Conflict of interest}

No potential conflict of interest relevant to this article was reported.

\section{Ethical approval}

The study was approved by the Institutional Review Board of Hamadan University of Medical Sciences (registration date: 2018-08-21) and performed in accordance with the principles of the Declaration of Helsinki. Written informed consents were obtained. This study was registered in the Iranian Registry of Clinical Trials with ID: IRCT20180707040370N2.

\section{Patient consent}

The patients provided written informed consent for the publication and the use of their images.

\section{References}

1. Kannan P, Chapple CM, Miller D, Claydon LS, Baxter $\mathrm{GD}$. Menstrual pain and quality of life in women with primary dysmenorrhea: rationale, design, and interventions of a randomized controlled trial of effects of a treadmill-based exercise intervention. Contemp Clin Trials 2015;42:81-9.

2. Chen HM, Chen $\mathrm{CH}$. Effects of acupressure on menstrual distress in adolescent girls: a comparison between Hegu-Sanyinjiao matched points and Hegu, Zusanli single point. J Clin Nurs 2010;19:998-1007. 


\section{Obstetrics \& Gynecology Science}

Vol. 62, No. 5, 2019

3. Meda A, Lamien CE, Millogo J, Romito M, Nacoulma OG. Therapeutic uses of honey and honeybee larvae in central Burkina Faso. J Ethnopharmacol 2004;95:103-7.

4. Potharaju J, Usha P. Prevalence of primary dysmenorrhea in young women-an institutional study. J Evol Med Dent Sci 2017;6:6948-51.

5. Jenabi E, Fereidoony B. Effect of Achillea millefolium on relief of primary dysmenorrhea: a double-blind randomized clinical trial. J Pediatr Adolesc Gynecol 2015;28:402-4.

6. Dmitrovic R, Kunselman AR, Legro RS. Sildenafil citrate in the treatment of pain in primary dysmenorrhea: a randomized controlled trial. Hum Reprod 2013;28:295865.

7. Sostres C, Gargallo CJ, Arroyo MT, Lanas A. Adverse effects of non-steroidal anti-inflammatory drugs (NSAIDs, aspirin and coxibs) on upper gastrointestinal tract. Best Pract Res Clin Gastroenterol 2010;24:121-32.

8. Shobeiri F, Nazari S, Nazari S, Jenabi E, Shayan A. Effect of Menstrugole on primary dysmenorrhea: a randomized clinical trial. Obstet Gynecol Sci 2018;61:684-7.

9. Jenabi E, Asle Toghiri M, Hejrati P. The comparison of the effects of antiplain of valeriana officinalis risom and mefenamic acid in relief of primary dismenorrhea. Iran J Obstet Gynecol Infertil 2012;15:42-7.

10. Amiri Farahani ËL, Hasanpoor-Azghdy SB, Kasraei H, Heidari T. Comparison of the effect of honey and mefenamic acid on the severity of pain in women with primary dysmenorrhea. Arch Gynecol Obstet 2017;296:27783.

11. Golder W. Propolis. The bee glue as presented by the Graeco-Roman literature. Wurzbg Medizinhist Mitt 2004;23:133-45.

12. Haji Sharifi A. Iranian encyclopedia of honey therapy.
Tehran: Hafeze Novin; 2013.

13. Bueno-Silva B, Alencar SM, Koo H, Ikegaki M, Silva GV, Napimoga $\mathrm{MH}$, et al. Anti-inflammatory and antimicrobial evaluation of neovestitol and vestitol isolated from Brazilian red propolis. J Agric Food Chem 2013;61:454650.

14. Koblovská R, Macková Z, Vítková M, Kokoska L, Klejdus B, Lapcík O. Isoflavones in the Rutaceae family: twenty selected representatives of the genera Citrus, Fortunella, Poncirus, Ruta and Severinia. Phytochem Anal 2008; 19:64-70.

15. Paulino N, Dantas AP, Bankova V, Longhi DT, Scremin A, de Castro SL, et al. Bulgarian propolis induces analgesic and anti-inflammatory effects in mice and inhibits in vitro contraction of airway smooth muscle. J Pharmacol Sci 2003;93:307-13.

16. Al-Waili NS. Effects of honey on the urinary total nitrite and prostaglandins concentration. Int Urol Nephrol 2005;37:107-11.

17. Al-Waili NS. Natural honey lowers plasma glucose, C-reactive protein, homocysteine, and blood lipids in healthy, diabetic, and hyperlipidemic subjects: comparison with dextrose and sucrose. J Med Food 2004;7:100-7.

18. Ajorpaz NM, Hafezi M, Salehi S, Tayebi A, Shenasa F, Zahtabchi S. Comparing the effect of pure and impure honey on severity of pain, amount of bleeding, and duration and interval of menstrual cycles in female students with primary dysmenorrhea. 2012;2:23-33.

19. Ostad SN, Soodi M, Shariffzadeh M, Khorshidi N, Marzban $\mathrm{H}$. The effect of fennel essential oil on uterine contraction as a model for dysmenorrhea, pharmacology and toxicology study. J Ethnopharmacol 2001;76:299304. 